\title{
The environmental impact of climate change adaptation: land use and water quality
}

\author{
Carlo Fezzi ${ }^{1,2}$, Amii R. Harwood ${ }^{2}$, Andrew A. Lovett ${ }^{2}$ and Ian J. Bateman ${ }^{2}$
}

forthcoming on Nature Climate Change

Encouraging adaptation is an essential aspect of the policy response to climate change ${ }^{1}$. Adaptation seeks to reduce the harmful consequences and harness any beneficial opportunities arising from the changing climate. However, given that human activities are the main cause of environmental transformations worldwide ${ }^{2}$, it follows that adaptation itself also has the potential to generate further pressures, creating new threats for both local and global ecosystems. From this perspective, policies designed to encourage adaptation may conflict with regulation aimed at preserving or enhancing environmental quality. This aspect of adaptation has received relatively little consideration in either policy design or academic debate. To highlight this issue, this paper analyzes the trade-offs between two fundamental ecosystem services which will be impacted by climate change: provisioning services derived from agriculture and regulating services in the form of freshwater quality. Results indicate that climate adaptation in the farming sector will generate fundamental changes in river water quality. In some areas, policies which encourage adaptation are expected to be in conflict with existing regulations aimed at improving freshwater ecosystems. These findings illustrate the importance of anticipating the wider impacts of human adaptation to climate change when designing environmental policies.

On a global scale, agriculture is the economic sector which is likely to bear the greatest financial impact as a result of climate change ${ }^{3}$. Farmers are expected to adapt by switching activities to those which are most profitable given the new conditions they will face. Since agriculture is one of the major drivers of freshwater quality ${ }^{2,4}$, these changes in farmland use have the potential to substantially alter water ecosystems. For example, agricultural inputs are responsible for nutrient overload and eutrophication in water bodies worldwide $\mathrm{e}^{2,5,6}$ and are a major focus of policy action (e.g. US Clear Water $\mathrm{Act}^{7}$, EU Water Framework Directive ${ }^{8}$ ). Understanding the impact of agricultural adaptation to

\footnotetext{
${ }^{1}$ Department of Economics, University of California San Diego (California, USA). Corresponding Author email: c.fezzi@uea.ac.uk.

${ }^{2}$ CSERGE, School of Environmental Sciences, University of East Anglia (UK).
} 
climate change on water quality is, therefore, essential for delivering harmonised and efficient policies (although, from a theoretical standpoint, if all the external effects of agriculture on the environment were correctly priced, i.e. internalized, the market would automatically deliver socially optimal outcomes).

An important feature of the relationship between farming and water quality is its strong spatial heterogeneity. Agricultural activities, adaptation options and environmental quality vary significantly over relatively small areas. Therefore, a meaningful analysis requires data reflecting this fine-scale variation, which would be irremediably overlooked if large-scale, aggregated data were employed ${ }^{9,10}$. Our empirical investigation focuses on Great Britain (GB), where detailed and long established information sources allowed us to assemble a unique dataset, spanning more than 40 years at a resolution of $2 \mathrm{~km}$ grid squares (400 ha). This constitutes about half a million spatially referenced, time-specific, land-use records (see methods and supplementary materials, SM, sections S1.2 and S2.2). Almost $80 \%$ of GB's land use is devoted to a very heterogeneous farming system, ranging from the intensive arable cropping of the English lowlands to the extensive grazing farms of the upland northern and western regions including much of Scotland and Wales. While water quality in GB freshwater bodies is subject to several EU Directives ${ }^{8,11}$, a large share of its rivers and lakes are still characterized by high nutrient concentrations which fail to comply with existing regulations.

Our analysis is based on an integrated framework linking a spatially-explicit econometric model of agricultural production to a statistical model of river water quality. Integrating economic models of land use change with environmental models predicting consequent impacts on multiple ecosystem services has been a focus of considerable recent research ${ }^{10,12,13,14,15}$. By integrating novel land use and water quality models, our analysis examines how adaptation to climate change in agriculture is expected to affect aquatic ecosystems. By examining how spatial heterogeneity in climate has influenced agricultural production decisions and farm income (farm gross margin, $\mathrm{FGM}^{12,16}$ ) to date, we project how farmers will adapt to future climate. To estimate resulting water quality impacts, we rely on spatially explicit statistical models linking land use to observed concentrations of nitrate $\left(\mathrm{NO}_{3}\right)$ and phosphate (as phosphorous, $\mathrm{P}$ ) in rivers.

Our agricultural production model builds upon a strand of research in agricultural economics ${ }^{16,17}$. We develop a structural econometric model with a flexible specification of the effects of climate on agricultural land use and production (SM, S1.3). Temperature and precipitation are represented via linear regression splines coupled with a fixed effect estimator to both control for un-observed missing variables and isolate the impact of climate. Even within the relatively small area of GB, variation in climatic and environmental conditions is sufficient to yield substantial differences in agricultural 
productivity and, hence, land use. These differences are captured by the model along with variation due to other drivers such as changes in policies and prices.

Figure 1 reports the estimated impact of temperature and precipitation on two illustrative land use shares (arable and temporary grassland) and on beef cattle rates (heads/ha). As shown in the upper row, arable is the dominant land use in low precipitation areas, with pastures becoming more common only as rainfall rises. Beef cattle stocking rates rise rapidly with precipitation (and the concomitant increase in pasture size) until rainfall reaches about $500 \mathrm{~mm}$, after which cattle rates begin to slowly decline as they are replaced by more resilient livestock such as sheep. Considering the effect of temperature, in the second row, we observe a positive relationship with the share of arable land, related to the effect on yield which, however, becomes gradually less steep and finally negative for the highest temperatures, confirming previous research findings ${ }^{3,12,16}$.

We analyze water quality via statistical models explaining observed river nitrate and phosphate concentrations as functions of the land use and the climate characterizing the land upstream from each water monitoring station, derived via the use of a Geographical Information System (GIS) (see methods). By including fixed effects, we estimate coefficients which are robust to potential unobserved confounders. The parameters of the final models are reported in Table 1.

The land share coefficients should be interpreted relative to the omitted land use category, which here is arable farming. Therefore, negative (positive) coefficients indicate that a land use produces less (more) pollution than arable. All parameters conform to our expectations and previous literature . $^{4,5,6}$. Considering nitrate, urban land yields levels of concentration which are not significantly different from those of arable, while other land uses generate lower leaching. In the extreme, an entirely arable catchment is predicted to generate average nitrate concentrations of just over $44 \mathrm{mg} \mathrm{NO}_{3} / \mathrm{l}$, which would be considerably above the threshold of $30 \mathrm{mg} \mathrm{NO}_{3} / 1$ identified by EU regulations ${ }^{8,11}$.

Similar consistency with previous research ${ }^{18}$ is confirmed within the model of phosphate. The estimates indicate that the main source of phosphorous in rivers is urban land, which has a coefficient almost three times higher than that of arable, again represented by the intercept. Nevertheless, the model suggests that a river catchment draining an entirely arable area would typically yield a concentration of about $0.39 \mathrm{mg} \mathrm{P} / 1$, or above the threshold of $0.2 \mathrm{mg} \mathrm{P} / 1$ recommended by the WFD ${ }^{8}$, while a fully urbanized catchment is predicted to yield concentrations averaging around $1.29 \mathrm{mg} \mathrm{P} / \mathrm{l}$. Again, less intensive land uses produce significantly lower concentrations.

We integrate the agricultural land use and river quality models and verify their performance in predicting observed data via out-of-sample testing (SM S3). In order to project the impact of climate 
change adaptation, we hold prices, policy and technological change constant at their baseline values. In addition, we also leave unchanged all non-agricultural land allocation and farm woodland, which is mainly driven by area-specific governmental and planning policies. Therefore, these scenarios are not projections of the future, but rather illustrate, ceteris paribus, the impact of climate change adaptation. In GB climate change is expected to generate a warmer and drier growing season, with average temperatures projected to increase by about $2^{\circ} \mathrm{C}$, and total precipitation to decrease, on average, by about $60 \mathrm{~mm}$, by the $2040 \mathrm{~s}^{19}$ (see also SM, Figure S3).

Figure 2 summarizes our findings for the baseline year and climate change scenarios in 2020s and 2040s. The first column of maps shows baseline conditions for agricultural production values (map A), concentrations of nitrate (D) and phosphate (G). Current agricultural production shows a clear SouthNorth divide, with the lowlands in the south being significantly more profitable than the colder and wetter regions in Scotland and Wales. Our results indicate that climate change will reduce this gap, primarily benefiting northern regions as higher temperatures will allow increases in more profitable arable and higher livestock intensity (maps B and C). However, such changes are also expected to amplify the pressure on the environment, increasing diffuse emissions into rivers. Overall, the area of land at risk of reporting high nitrate and high phosphate concentrations is projected to increase by $30 \%$ (1.4 million ha) and 20\% (1.6 million ha) respectively, as a result of climate change adaptation (SM S4.3). These areas are illustrated in red in maps E, F, H and I. This indicates that adaptation will significantly increase the effort required to achieve water quality standards, particularly in the eastern uplands and midlands where temperature rises will permit significant increases in agricultural production.

Map A in Figure 3 summarizes the spatially heterogeneous effects of climate change adaptation on agricultural incomes and water quality by the 2040s. Areas where adaptation to climate change will yield improvements in farming without significant environmental repercussions are shown in green (including most of the North-West but the highest upland regions). Other areas, which are not expected to yield reductions in water quality but are predicted to see falls in farm income are shown in orange (principally in the south of England). The map also reveals areas of trade-off, either regions where adaptation is expected to raise FGM at the expense of generating high nutrient concentrations (shown in red in areas such as the North-Eastern coast and across parts of the English midlands), or where losses in farm income will be accompanied by improvements in water quality (blue areas in the south). Remaining areas are not expected to experience substantial changes in either farm incomes or diffuse pollution.

In considering a potential policy response to the problem of adaptation-induced deterioration of river water quality, an option within the British context is provided by recent government announcements 
regarding an intention to significantly extend woodland coverage over the next decades ${ }^{20,21}$. Among the diverse set of benefits which can be generated by forests (including carbon storage, recreational provision, timber output, etc.), this initiative also views water quality enhancements as a key argument for woodland creation, given the very low nutrient leaching rates generated by this land use. Therefore, we examine the effect of locating the woodland in those areas where adaptation is expected to generate the largest falls in water quality. Map C in Figure 3 shows planting locations for 500,000ha of new forests (a level consistent with policy discussions) ${ }^{20,21}$ while central Map B reveals the environmental and economic impacts of such a policy (results for different planting acreages are given in SM Table S8). The effects are very significant, with almost all rivers in the targeted areas projected to remain in good condition despite the increase in agricultural production. This demonstrates how a systemic approach to interventions can anticipate the environmental impacts of climate change adaptation and deliver more than one policy-goal at the same time.

As our discussion suggests, the potential effects of adaptation in the farming sector are not restricted to water quality. Adaptation may impact on water availability, wildlife, biodiversity, carbon sequestration, recreation, etc. On the other hand, climate change could also reduce the viability of agriculture in some areas, potentially diminishing certain pressures. Furthermore, the environmental impacts of adaptation are not limited to farming, but concern most activities which will be impacted by climate change, including energy demand and production ${ }^{22}$, fisheries ${ }^{23}$, forestry ${ }^{24}$ and health ${ }^{25}$. This of course does not imply that adaptation is inappropriate, rather it demonstrates that policies should take into account the wider implications of adaptation and seek to incorporate such synergies and trade-offs. This will require a degree of integration across policy fields which is still lacking in current decision making ${ }^{26}$.

\section{Methods}

Land use model. The large database used for estimating the agricultural land use model was assembled using a variety of spatially explicit information. Land use and livestock data were derived from the June Agricultural Census (source, EDINA, www.edina.ac.uk). Collected on a $2 \mathrm{~km}$ grid square (400ha) basis, this covers the entirety of GB for ten unevenly spaced years from 1972 to 2004. This constitutes roughly 55,000 grid-square records per year, amounting to over 500,000 grid-square observations for the overall analysis. We consider four categories of land use, each associated with different levels of pollution: (a) temporary grassland, (b) permanent grassland, (c) rough grazing and (d) arable (definitions in SM 1.2). We include three livestock types: dairy cattle, beef cattle and sheep. Environmental drivers of agricultural land use include average temperature and accumulated rainfall, 
environmental and topographic variables, policies etc. Yearly and regional fixed effects allow us to control for time- and spatially-varying omitted factors (see SM 1.2).

We assume that farmers choose their land use activities $\left(l_{h}\right)$ by taking into account expected input (p) and output (w) prices, policy constraints, climate and land quality (all included in the vector $\mathbf{z}$ ). The agricultural land within each $400 \mathrm{ha}$ cell is modelled as an individual farm characterized by a multiproduct profit $(\pi)$ function, which is maximized according to the following objective function:

$\pi(\mathbf{p}, \mathbf{w}, \mathbf{z}, L)=\max _{l_{1}, \ldots, l_{h}}\left\{\pi\left(\mathbf{p}, \mathbf{w}, \mathbf{z},, l_{1}, \ldots, l_{h}\right): \sum_{i=1}^{h} l_{h}=L\right\}$

Using a normalized quadratic empirical specification for $\pi^{t}$ and applying Hotelling's lemma, we derive land use share equations and land use intensity equations in linear forms ${ }^{12,16}$ (SM S1.3). For instance, if $p_{i}$ indicates the price of cereals, the equation corresponding to cereal yield $y_{i}$ is:

$\frac{\partial \pi}{\partial p_{i}}=y_{i}=k_{i}+\mathbf{z}^{\prime} \boldsymbol{\alpha}_{i}+\mathbf{p}^{\prime} \boldsymbol{\beta}_{i}+\mathbf{w}^{\prime} \boldsymbol{\gamma}_{i}$

where $k_{i}, \boldsymbol{\alpha}_{i}, \boldsymbol{\beta}_{i}, \boldsymbol{\gamma}_{i}$ are the parameters of the cereal yield equation to be estimated. As our data contains corner solutions (not all farms cultivate all possible crops), adding Gaussian disturbances and implementing ordinary least squares or generalized least square estimation leads to inconsistent results. Therefore, we implement a quasi maximum likelihood, heteroskedastic, simultaneous equation, Tobit model ${ }^{12,27}$. Predictive performance is tested via a rigorous out-of-sample forecasting exercise (SM 1.3, 1.4, Table S1, Figure S1).

Water quality model. Data on nitrate and phosphate concentration are extracted for over 5,000 monitoring points collected as part of the General Quality Assessment (GQA) survey conducted annually by the Environment Agency to monitor the state of GB freshwater ecosystems ${ }^{28}$. We selected data averages for the years 2005 to 2007 to fall within the period of our land cover and land use intensity information (see below and SM 2.2). Since monitoring points can refer to stations located on the same river, or to rivers belonging to the same catchment, nutrient concentrations can be spatially dependent across stations. To implement standard statistical modelling on a sample of independent observations, we select a smaller sub-sample of 214 stations belonging to non-overlapping catchments representing the locations and the range of nitrate levels observed in the full sample (Figure S2 and Table S2). GQA data classify nutrient levels as belonging to one of six categories from very low concentrations of pollution (highest water quality) to very high levels (worst quality), as detailed in SM 2.2. Given the structure of this data, we model concentrations for nutrient $q$ (nitrate or phosphate) 
at point $j$ using interval regression techniques, which are generalizations of the censored Tobit model $^{27}$, as follows:

$$
N_{q, j}==\mathbf{x}_{j q}^{\prime} \mathbf{b}_{q}+e_{j q}
$$

where $\mathbf{x}_{j q}$ indicates the matrix of explanatory variables, $e_{j q}$ indicates an identically distributed residual term and $\mathbf{b}_{q}$ is the vector of parameters to be estimated. As explanatory variables we consider land use (arable, improved grassland, rough grassland, forest and urban), livestock intensity and population upstream from each GQA monitoring point, derived by weighted flow accumulation techniques ${ }^{29}$ (see SM 2.2). We include regional fixed effects to account for spatial omitted variables. Different model specifications with corresponding goodness of fit measures are reported in SM, Table S3.

Integrated framework: The land use model and the water quality model are estimated using the same spatial units and variable definitions. This ensures that a full integration of the two models is relatively straightforward. This integrated framework is verified via out-of-sample predictions (SM 3, Table S4 and Figure S3).

Climate change scenarios. We consider medium emission ${ }^{30}$ climate change scenarios published by $\mathrm{UKCIP}^{19}$ as $25 \mathrm{~km}$ grid square projections for the '2020s' (defined as the average climate between years 2010-2039) and '2040s' (2030-2059) periods. Consistent with UKCIP, we use as a baseline the climate averages for the years 1961-1990. (SM 4). Table S5 provides descriptive statistics of the climatic variables in the historical baseline and in each scenario, which are also represented via maps in Figure S4. Table S6 provides descriptive statistics of our land use projections, Table S7 reports projection of nutrients' concentrations.

\section{Acknowledgements}

This research was supported by the LUCES Project (Project id: 302290), funded by the European Commission under the Marie Curie International Outgoing Fellowship Programme, the SEER Project, funded by the ESRC (ref: RES-060-25-0063) and WEPGN, Brock University. Many thanks to Richard Carson, Silvia Ferrini, Kurt Schwabe for their helpful comments on a previous version of this paper. Thanks to Anthony De-Gol for his assistance with the UKCIP data.

\section{Authors' contributions}

The analysis was designed by C.F with contributions from I.J.B and all the authors, A.R.H. and A.A.L. undertook the GIS analysis, the data collection and integration, C.F. undertook the econometric 
analysis of the land use and the water quality models, C.F. and I.J.B. wrote the paper with contributions from all the authors.

\section{Competing financial interests}

The authors declare no competing financial interests.

\section{References}

[1] Pielke, R., Prins, G.P., Rayner, S. \& Sarewitz, D. (2007) Lifting the taboo on adaptation, Nature, vol. 445, pp. 597-598.

[2] Vitousek P.M., Mooney H.A., Lubchenco J., Melillo J.M. (1997) Human domination of earth's ecosystems, Science, vol. 277, n. 5325, pp. 494-499.

[3] Lobell D.B, Schlenker W., Costa-Roberts J. (2011) Climate trends and global crop production since 1980, Science, vol. 333, n. 6042, pp. 616-620.

[4] Sterling S. M., Ducharne A., Polcher J. (2013) The impact of global land-cover change on the terrestrial water cycle, Nature Climate Change, vol. 3, pp. 385-390.

[5] McIsaac G.F., David M.B., Gertner G.Z., Goolsby D.A. (2001) Eutrophication: Nitrate flux in the Mississippi River, Nature, vol. 414, pp. 166-167.

[6] Conley D.J. (2012) Ecology: save the Baltic Sea, Nature, vol. 486, pp. 463-464.

[7] Environmental Protection Agency (2012) Water quality standards Handbook: Second Edition, EPA-823-B-12-002.

[8] European Commission (2000) Directive 2000/60/EC (Water Framework Directive), Official Journal, 22 December 2000.

[9] Willis K.J., Bhagwat S.A. (2009) Biodiversity and climate change, Science, vol.326, n. 806, pp. 806-807.

[10] Goldstein J. H., Caldarone G., Duarte T.K., Ennaanay D., Hannahs N., Mendoza G., Polasky S., Wolny S., Daily G.C. (2012) Integrating ecosystem-service tradeoffs into land-use decisions, Proceedings of the National Academy of Science, vol. 109, n. 19, pp. 7565-7570.

[11] European Commission (1991) Directive 91/676/EEC (Nitrates Directive), Official Journal, 12 December 1991.

[12] Bateman I.J., Harwood A., Mace G., Watson R.T., Abson D., Andrews B., Binner A., Crowe A., Day B., Dugdale S., Fezzi C., Foden J., Hadley D., Haines-Young R., Hulme M., Kontoleon A., Lovett A., Munday P., Pascual U., Paterson J., Perino G., Sen A., Siriwardena G., Van Soest D., Termansen M. (2013) Bringing ecosystem services into economic decision making: Land use in the UK, Science, vol. 314, n. 6141, pp. 45-50. 
[13] Lawler J.J., Lewis D.J., Nelson E., Plantinga A.J., Polasky S., Withey J.C., Helmers D.P., Martinuzzi S., Pennington D., Radeloff V.C. (2014) Projected land-use impacts on ecosystem services in the United States, Proceedings of the National Academy of Science, vol. 111, pp. 74927497.

[14] Johnson J.A., Runge C.F., Senauer B., Foley J., Polasky S. (2014) Global agriculture and carbon trade-offs, Proceedings of the National Academy of Science, vol. 111, pp. 12342-12347.

[15] Polasky S., Lewis D., Plantinga A., Nelson E. (2014) Implementing the optimal provision of ecosystem services, Proceedings of the National Academy of Sciences, vol. 111, pp. 6248-6253.

[16] Fezzi, C. and Bateman, I.J. (2011) Structural agricultural land use modeling for spatial agroenvironmental policy analysis, American Journal of Agricultural Economics, vol. 93, pp. 11681188.

[17] Kling C., (2011) Economic Incentives to Improve Water Quality in Agricultural Landscapes: Some New Variations on Old Ideas, American Journal of Agricultural Economics, vol. 93, pp. 297309.

[18] Jarvie H.P., Neal C., Withers P.J.A. (2006) Sewage-effluent phosphorus: A greater risk to river eutrophication than agricultural phosphorus? Science of the Total Environment, vol. 360, pp. 246253.

[19] UK Climate Impacts Programme (UKCIP) (2009) UK climate projection: briefing report, Met Office Hadley Centre, Exeter, UK.

[20] Defra (2013) Government forestry and woodlands policy statements incorporating the government's response to the independent panel on forestry's final report, https://www.gov.uk/ government/publications/government-forestry-policy-statement (September 2014)

[21] Natural Capital Committee (2014) The State of Natural Capital: Restoring our Natural Assets, Second report to the Economic Affairs Committee, Defra, London, available from http://www.defra.gov.uk/naturalcapitalcommittee/.

[22] De Cian E., Lanzi E., Roson R. (2013) Seasonal temperature variations and energy demand: A panel cointegration analysis for climate change impact assessment, Climatic Change, vol. 116, pp. 805-825.

[23] Barange M., Merino G., Blanchard J. L., Scholtens J., Harle J., Allison E.H., Allen J.I., Holt J., Jennings S. (2014) Impacts of climate change on marine ecosystem production in societies dependent on fisheries, Nature Climate Change, vol. 4, pp. 211-216.

[24] Guo C., Costello C. (2013) The value of adaptation: Climate change and timberland management, Journal of Environmental Economics and Management, vol. 65, pp. 452-468.

[25] Patz J.A., Campbell-Lendrum D., Holloway T., Foley J.A. (2005) Impact of regional climate change on human health, Nature, vol. 438, pp. 310-317.

[26] Nisson M., Zamparutti T., Petersen J.E., Nykvist B., Rudberg P., McGuinn J. (2012) Understanding Policy Coherence: Analytical Framework and Examples of Sector-Environment Policy Interactions in the EU, Environmental Policy and Governance, vol. 22, pp. 395-423.

[27] Amemiya T. Regression Analysis When the Dependent Variable Is Truncated Normal. Econometrica 1973;41:997-1016. 
[28] EA-AfA163 (2012) GQA Headline indicators of water courses (nutrients), Environment Agency, Bristol.

[29] Kennedy, M. (2009) Introducing Geographic Information Systems with ArcGIS, John Wiley, New Jersey, pp. 433-443.

[30] Nakicenovic N., Swart R. (2000) Special Report on Emissions Scenarios, Cambridge University Press, Cambridge. 
Table 1: Water quality models

\begin{tabular}{|c|c|c|}
\hline & Nitrate & Phosphate \\
\hline Intercept & $\begin{array}{c}46.48^{* * *} \\
(2.57)\end{array}$ & $\begin{array}{c}0.389^{* * * *} \\
(0.056)\end{array}$ \\
\hline share $_{\text {urban }}$ & $\begin{array}{l}-4.24 \\
(20.08)\end{array}$ & $\begin{array}{c}0.897^{* * *} \\
(0.137)\end{array}$ \\
\hline share $_{\text {rough }}$ & $\begin{array}{c}-40.23^{* * * *} \\
(7.43)\end{array}$ & $\begin{array}{l}-0.485^{*} \\
(0.246)\end{array}$ \\
\hline share $_{\text {grass }}$ & $\begin{array}{c}-37.94^{* * *} \\
(9.47)\end{array}$ & $\begin{array}{c}-0.311^{* *} \\
(0.132)\end{array}$ \\
\hline share $_{\text {wood }}$ & $\begin{array}{c}-34.64^{* * * *} \\
(9.31)\end{array}$ & $\begin{array}{l}-0.589^{*} \\
(0.339)\end{array}$ \\
\hline $\mathrm{D}_{\text {livestock }} *$ share $_{\text {grass }}$ & $\begin{array}{l}10.38^{* *} \\
(4.93)\end{array}$ & - \\
\hline $\mathrm{D}_{\text {pop }} *$ share $_{\text {urban }}$ & $\begin{array}{c}0.18 \\
(0.53)\end{array}$ & - \\
\hline precipitation & $\begin{array}{c}-0.62^{* *} \\
(0.92)\end{array}$ & - \\
\hline$\sigma$ & $\begin{array}{l}7.47^{* * * *} \\
(0.39)\end{array}$ & $\begin{array}{l}0.231^{* * *} \\
(0.011)\end{array}$ \\
\hline Log-Likelihood & -286.26 & -439.60 \\
\hline Pseudo $\mathrm{R}^{2}$ (McFadden) & 0.28 & 0.10 \\
\hline
\end{tabular}

Notes: Interval regression model estimated with Gaussian residuals on 214 monitoring points located on independent river catchments. Coefficients need to be interpreted using the share of arable land as the baseline category. $\mathrm{D}_{\text {livestock }}$ is the livestock density (number of cattle per hectare of grassland), $\mathrm{D}_{\mathrm{pop}}$ is the population intensity (defined as the number of people per hectare). Significance levels: $" * "=0.10, " * * "=0.05, " * * * "=0.01$. 
Figure 1: Estimated impact of total precipitation $(\mathrm{mm})$ and average temperature $\left({ }^{\circ} \mathrm{C}\right)$ during the growing season (April-September) on land use shares $(\%$ agricultural area) and beef cattle stocking rates (heads/ha)
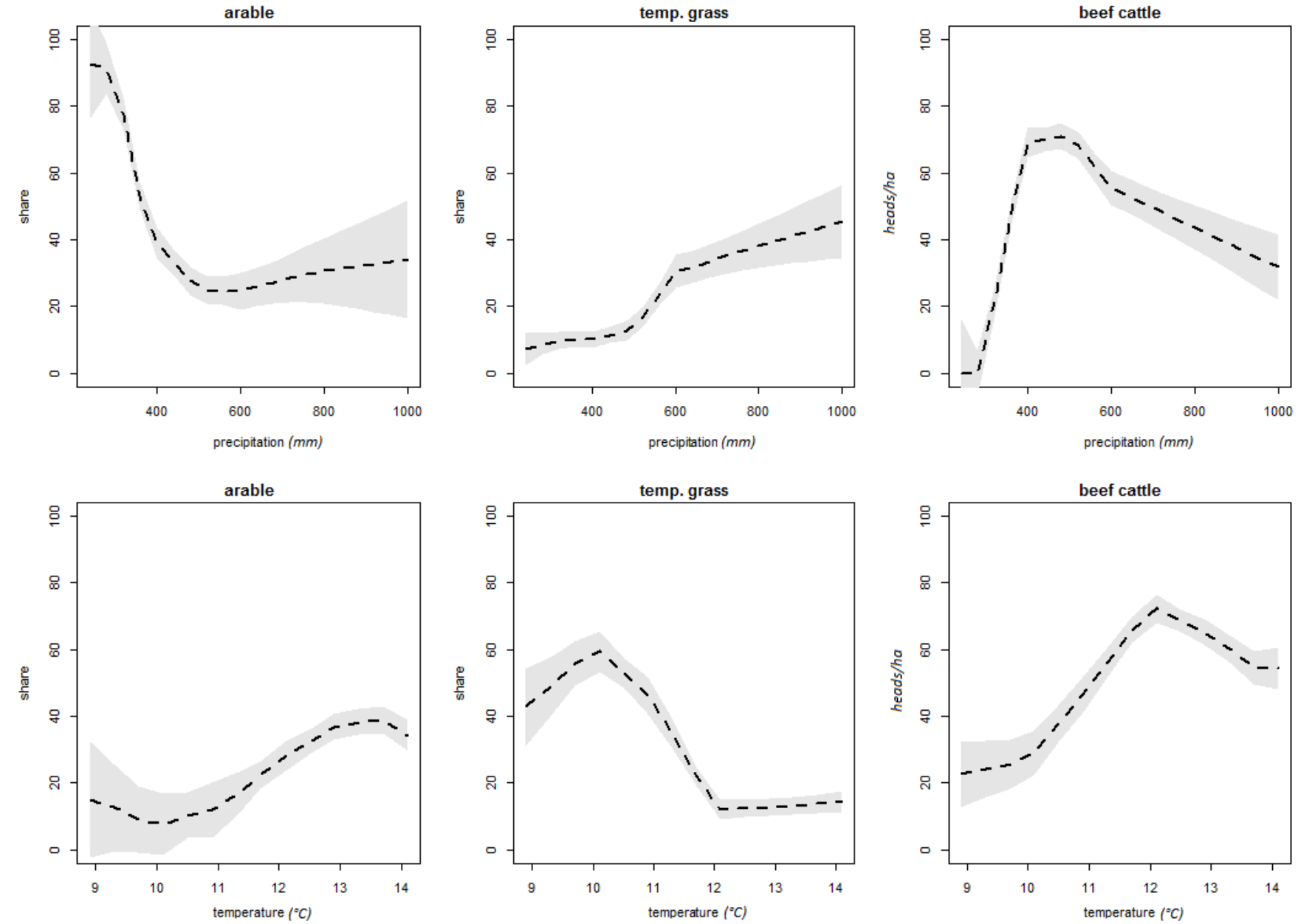

Notes: Dashed lines indicate estimated relations, gray areas the $95 \%$ asymptotic confidence intervals. All other explanatory variables are fixed at the sample mean. 
Figure 2: Impact of climate change (UKCP09 medium emission, SRES A1 B scenario) for the 2020s, and 2040s on farm gross margin (£/ha) and river quality $\left(\mathrm{NO}_{3} ; \mathrm{P}\right)$.
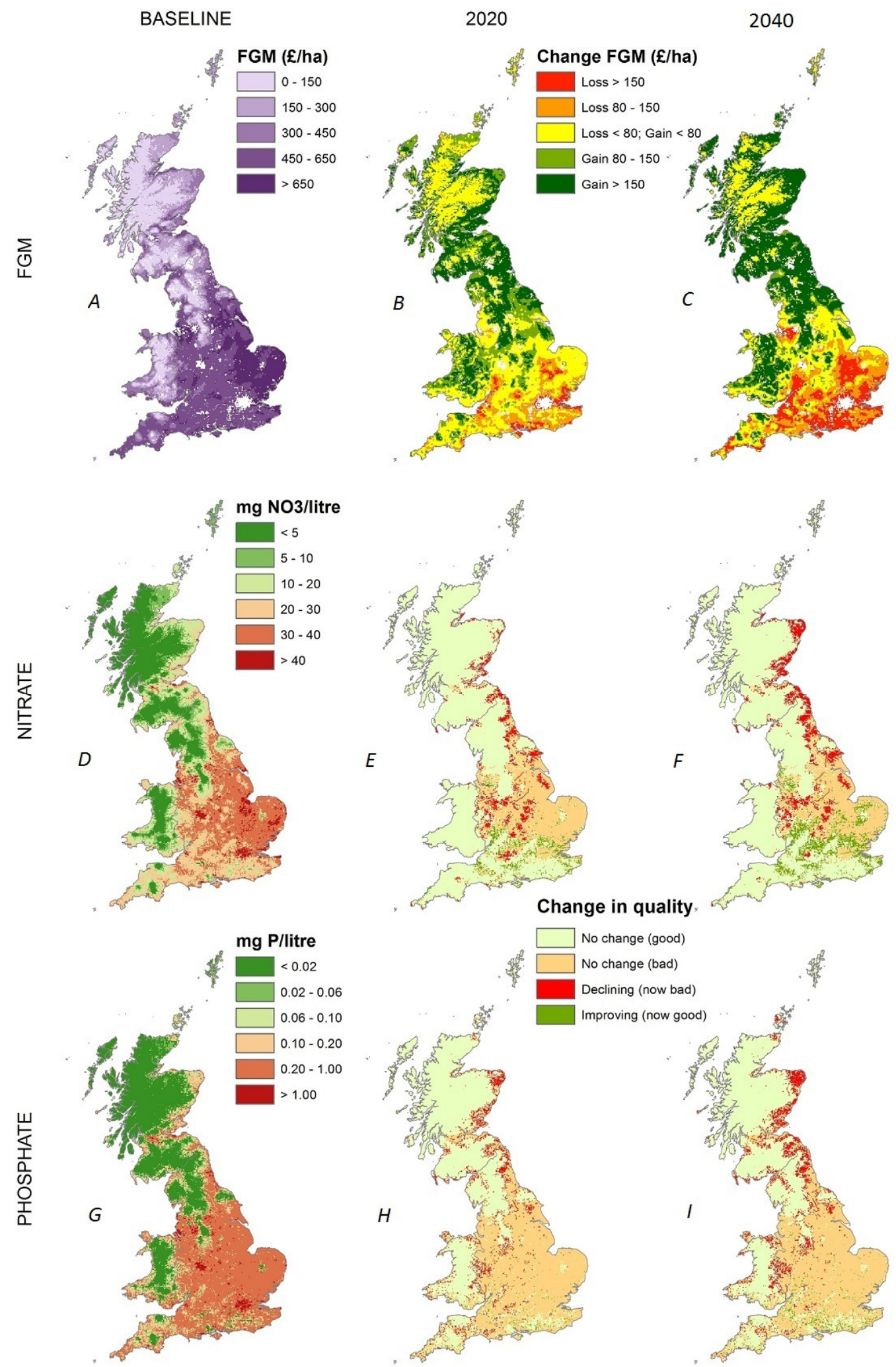

Notes: The first column (maps A, D, G) presents estimated values for the baseline climate. The second (maps B, E, H) and third (maps C,F,I) columns present projected changes for the 2020s and 2040s (UKCIP medium emission scenarios). The 2020s and 2040s are defined respectively as the climate averages for the years 2010-2039 and 2030-2059 as by the UKCIP ${ }^{22}$. 
Figure 3: The impact of climate change adaptation and possible policy response

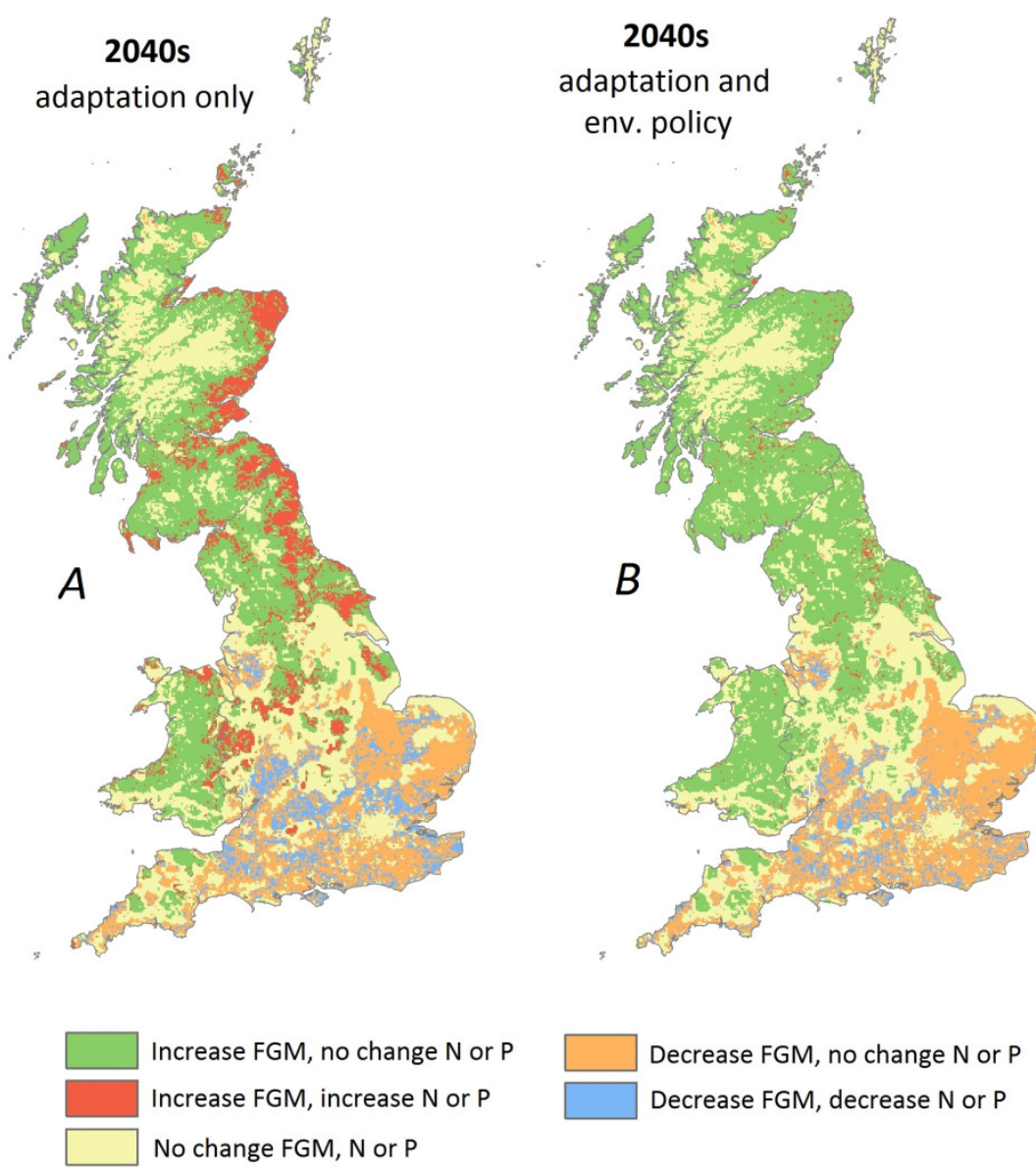

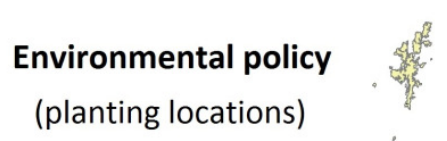

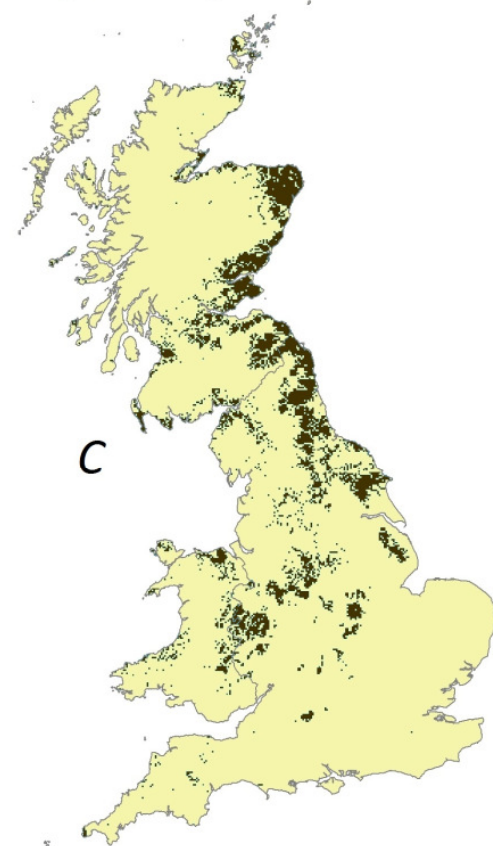

Planting locations

Notes: Map A shows areas of significant increase (decrease) in profit defined as FGM change $>(<)$ 80£/ha (see Figure 2), and water quality with decreases defined as cases where $\mathrm{N}$ or $\mathrm{P}$ concentrations are low or moderate in the baseline (i.e. lower than $30 \mathrm{mg} \mathrm{NO} / \mathrm{l}$ and $0.2 \mathrm{mg}$ P/l respectively, see SM, section S2) and become high in the climate change and agricultural adaptation scenario (the converse applies for the definition of water quality improvement). Map B illustrates these various changes following the introduction of a policy response consisting of the planting of 500,000 hectares of new broadleaf forests in the locations indicated in Map C. The 2040s period is defined as the climate averages for the years $2030-2059$ as given by UKCIP $^{19}$. 